Goeij, de M.C.M., Suhrcke, M., Toffolutti, V., Mheen, D. van de, Schoenmakers, T.M., Kunst, A.En How economic crises affect alcohol consumption and alcohol-related health problems: a realist systematic review. Social Science \& Medicine: 2015, 131(1), 131-146

\begin{tabular}{|l|l|}
$\begin{array}{l}\text { Postprint } \\
\text { Version }\end{array}$ & 1.0 \\
\hline Journal website & http://www.sciencedirect.com/science/article/pii/S0277953615001082 \\
\hline Pubmed link & http://www.ncbi.nlm.nih.gov/pubmed/25771482 \\
\hline DOI & $10.1016 /$ j.socscimed.2015.02.025
\end{tabular}

This is a NIVEL certified Post Print, more info at http://www.nivel.eu

\title{
How economic crises affect alcohol consumption and alcohol-related health problems: A realist systematic review
}

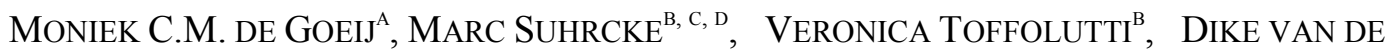
MHEEN $^{\mathrm{E}, \mathrm{F}, \mathrm{G}}$, TIM M. SCHOENMAKERS ${ }^{\mathrm{E}, \mathrm{F}}$, ANTON E. KUNST ${ }^{\mathrm{A}}$

a Department of Public Health, Academic Medical Center (AMC) - University of Amsterdam, PO Box 22660, 1100 DD Amsterdam, The Netherlands

b Health Economics Group, Norwich Medical School, University of East Anglia, Norwich, Norfolk NR4 7TJ, United Kingdom

c United Kingdom Clinical Research Collaboration (UKCRC) Centre for Diet and Activity Research (CEDAR), Institute of Public Health, Cambridge CB2 0SR, United Kingdom

d Centre for Health Economics, University of York, Heslington, York YO10 5DD, United Kingdom

e IVO Addiction Research Institute, Heemraadssingel 194, 3021 DM Rotterdam, The Netherlands

f Erasmus MC - University Medical Center Rotterdam, PO Box 2040, 3000 CA Rotterdam, The Netherlands

g Maastricht University, Department of Health Promotion, PO Box 616, 6200 MD Maastricht, The Netherlands

\begin{abstract}
Economic crises are complex events that affect behavioral patterns (including alcohol consumption) via opposing mechanisms. With this realist systematic review, we aimed to investigate evidence from studies of previous or ongoing crises on which mechanisms (How?) play a role among which individuals (Whom?). Such evidence would help understand and predict the potential impact of economic crises on alcohol consumption. Medical, psychological, social, and economic databases were used to search for peer-reviewed qualitative or quantitative empirical evidence (published January 1, 1990-May 1, 2014) linking economic crises or stressors with alcohol consumption and alcohol-related health problems. We included 35 papers, based on defined selection criteria. From these papers, we extracted evidence on mechanism(s), determinant, outcome, country-level context, and individual context. We found 16 studies that reported evidence completely covering two behavioral mechanisms by which economic crises can influence alcohol consumption and alcohol-related health problems. The first mechanism suggests that psychological distress triggered by unemployment and income reductions can increase drinking problems. The second mechanism suggests that due to tighter
\end{abstract}


Goeij, de M.C.M., Suhrcke, M., Toffolutti, V., Mheen, D. van de, Schoenmakers, T.M., Kunst, A.En How economic crises affect alcohol consumption and alcohol-related health problems: a realist systematic review. Social Science \& Medicine: 2015, 131(1), 131-146

budget constraints, less money is spent on alcoholic beverages. Across many countries, the psychological distress mechanism was observed mainly in men. The tighter budget constraints mechanism seems to play a role in all population subgroups across all countries. For the other three mechanisms (i.e., deterioration in the social situation, fear of losing one's job, and increased nonworking time), empirical evidence was scarce or absent, or had small to moderate coverage. This was also the case for important influential contextual factors described in our initial theoretical framework. This realist systematic review suggests that among men (but not among women), the net impact of economic crises will be an increase in harmful drinking. Such a different net impact between men and women could potentially contribute to growing gender-related health inequalities during a crisis.

\section{INTRODUCTION}

In the public health community, concerns have been expressed about negative health consequences associated with the current economic crisis in Europe (WHO, 2009). This crisis started in 2008 as a result of decreasing mortgage-backed security values during previous years in the United States (US) (Obstfeld and Rogoff). In the US this led to rising interest rates, borrower and bank defaults, and a crash in the housing and stock markets. Because many of these mortgage-backed securities were sold in Europe, this also triggered an economic crisis there. Another trigger for the European economic crisis has been the collapse of the US import market, which produced serious consequences for the European export market and economy (Blanchard et al., 2010). From 2008 onwards, gross domestic product (GDP) decreased, unemployment rates increased, and public budget deficits rose substantially (Eurostat, 2012). In response to the economic crisis, many European countries introduced major policy changes (Karanikolos et al., 2013), which may have influenced public health on top of the influence that the economic decline itself may have had (Stuckler and Basu, 2013).

Alcohol consumption (in terms of volume and pattern) and alcohol-related health problems (e.g., alcohol abuse, and dependence) are public health issues that can be positively or negatively affected by economic crises. Changes in alcohol consumption can have a considerable effect on public health and societal welfare (Anderson et al., 2009), as total alcohol consumption is causally related to many chronic medical conditions like cancer, mental disorders, and cardiovascular diseases (Rehm et al., 2003 and Rehm et al., 2008). Moreover, large numbers of drinking occasions and binge drinking can lead to either intentional or unintentional injuries, resulting from things such as violent behavior, suicide, homicide, and traffic accidents (Rehm et al., 2003; Taylor et al., 2008). There are also substantial indirect effects of alcohol-related health problems such as job loss, crime, and social exclusion (van Amsterdam and van den Brink, 2013).

The empirical evidence on the impact of economic crises on alcohol consumption and alcohol-related health problems is mixed. Alcohol consumption increased following the start of the economic and social transition in Russia and other Eastern European countries in the early 1990s, and this coincided with an increase in mortality and accidents (Baker, 2011, Men et al., 2003 and Wojtyniak et al., 2005). This may be related to the strong binge drinking culture in Eastern Europe (Rechel 
Goeij, de M.C.M., Suhrcke, M., Toffolutti, V., Mheen, D. van de, Schoenmakers, T.M., Kunst, A.Ef How economic crises affect alcohol consumption and alcohol-related health problems: a realist systematic review. Social Science \& Medicine: 2015, 131(1), 131-146

et al., 2013). Moreover, the Gorbachev anti-alcohol campaign ended just before the start of the Russian transition, and this led to lower alcohol prices (Bhattacharya et al., 2013). During this same time period Finland experienced an economic crisis, which led to mass unemployment. However, in contrast with the transition in Eastern Europe, the crisis in Finland coincided with a reduction in alcohol consumption and alcohol-related mortality (Herttua et al., 2007, Hintikka et al., 1999 and Valkonen et al., 2000). A reduction in alcohol consumption also followed the economic slowdown in Australia in the early 1990s (Chalmers and Ritter, 2011). The crisis in Southeast Asia in the late 1990s led to an increase in suicide rates, but alcohol consumption remained stable (Chang et al., 2009). These opposing trends support the notion that both specific characteristics of the crisis and the country-level context can influence how an economic crisis may exert an effect on alcohol consumption and alcohol-related health problems.

Economic crises can increase anxiety, stress, and depression (Wahlbeck and McDaid, 2012), for example, as a result of income reductions and/or loss of employment and the subsequent loss of social status and relationships. Two related psychological theories explain how these crises-triggered consequences could increase levels of alcohol consumption and the incidence of alcohol-related health problems. The "stress-response-dampening theory" argues that individuals consume alcohol to reduce the intensity of their response to anxiety and stress, which results in higher levels of alcohol consumption during economic crises (Sayette, 1999, Sher et al., 2007 and Sher and Levenson, 1982). The "self-medication theory" argues that alcohol-related health problems may increase during economic crises because consuming alcohol to cope with such stressful situations can lead to the development of dependency in certain people (Bolton et al., 2009 and Khantzian, 1997). Theories from other fields, including economics and sociology, offer different explanations. One basic economic theory suggests that income reductions will result in tighter individual budget constraints, so that less money will be spent on normal goods, including alcoholic beverages (i.e., the "income-effect theory") (Catalano, 1997 and Ruhm, 1995). According to the "non-working time theory", a decrease in working hours (either due to job loss or fewer tasks at work) will lead to more time for social events, sports activities, and watching television. It is known that these activities are often accompanied by alcohol consumption (French et al., 2009). These theories may suggest that the impact of economic crises on alcohol consumption depends on a person's economic and social situation.

The contradictory empirical evidence and the variety of theories suggest that an economic crisis is a complex event that affects behavioral patterns (such as drinking) via various potentially opposing mechanisms. Therefore, the overall net impact is hard to predict and may well differ between countries and between subgroups within a population. To facilitate such predictions, we need evidence on which mechanisms play a role in which context and in which subgroup within a population. Such evidence would contribute to an understanding of how the current post-2008 economic crisis in Europe (but also other crises) may have had an impact on alcoholrelated health problems. In addition, such evidence can help to determine which policies (e.g., increase in alcohol prices, or a restriction in alcohol availability (WHO, 2011)) can best be implemented during economic crises to change the presence of behavioral mechanisms and prevent an increase in the prevalence of 
Goeij, de M.C.M., Suhrcke, M., Toffolutti, V., Mheen, D. van de, Schoenmakers, T.M., Kunst, A.Ef How economic crises affect alcohol consumption and alcohol-related health problems: a realist systematic review. Social Science \& Medicine: 2015, 131(1), 131-146

excessive alcohol use. Such evidence can also be used to identify those subgroups most at risk of increased drinking during times of crisis.

In light of the above, the aim of our review was to investigate how economic crises affect levels of alcohol consumption and the incidence of alcohol-related health problems, and whom this affects. This was innovative, as little research is being done that assesses the role of specific mechanisms or tries to empirically discriminate between mechanisms (Catalano, 1997). The complexity of the topic makes a systematic review using the realist evaluation methodology (Pawson, 2006) suitable for our research question. The realist evaluation method tries to answer how, under what circumstances, and among whom certain policies or changed conditions have an effect on a specific outcome. It is a theory-driven method. First, an initial theoretical framework is constructed on how a changed condition can have an impact in a certain context and in certain subgroups within a population. The theoretical framework focuses on providing insight into the "inner workings" of a certain changed condition. Then, different types of evidence are collected to confirm, refute, or refine this initial theoretical framework. We used both quantitative and qualitative empirical evidence from different disciplines, including public health, social psychology, and economics.

\section{Methods}

According to Pawson (2006), a realist systematic review should follow six steps: 1) Identify the research question, 2) Formulate the initial theoretical framework, 3) Search for primary studies, 4) Select studies and appraise study quality, 5) Extract, analyze, and synthesize relevant data, and 6) Refine the theoretical framework. These six steps were applied throughout our paper. In addition, our research was guided by Realist And Meta-narrative Evidence Syntheses: Evolving Standards (RAMESES) publication standards (Wong et al., 2013).

\subsection{Identifying the research question}

Our initial primary research question was as follows: How did the post-2008 economic crisis affect alcohol consumption and alcohol-related health problems in Europe, and whom did this affect? We explored key publications to assess the extent to which this question could be addressed with the available literature. As a result, we modified our primary research question in two ways. First, we extended our focus to previous crises and crises outside of Europe because not enough literature would be available otherwise. Only four of the papers included in this review investigated the post-2008 economic crisis in Europe. Furthermore, these other crises could provide relevant information on mechanisms that could be used during the process of building and refining our theory. Second, we chose to focus on the short-term effects of economic crises in the adult population ( $\geq 18$ years). Crises can affect many different populations (e.g., children, adolescents, the working-age population, and pensioners) in the shorter or longer term. For example, alcohol dependence during adulthood may be a long-term effect of being exposed to financial stressors and parental alcohol-related problems during childhood. Our final research question was as follows: How did economic crises produce short-term effects on alcohol consumption and alcohol-related health problems in the adult population, and who was affected? We assumed that an economic crisis could be identified by rising unemployment rates, falling GDP, or both. 
Goeij, de M.C.M., Suhrcke, M., Toffolutti, V., Mheen, D. van de, Schoenmakers, T.M., Kunst, A.Ef How economic crises affect alcohol consumption and alcohol-related health problems: a realist systematic review. Social Science \& Medicine: 2015, 131(1), 131-146

\subsection{Formulating the initial theoretical framework}

Information used for our initial theoretical framework was obtained through a scoping search of gray and published literature (the latter comprising mainly literature reviews (Anderson et al., 2009, Catalano, 1997, Morris et al., 2005 and Stuckler et al., 2009a)). To check whether our formulated initial framework was complete we gave presentations at two meetings with about 15 experts from the field of health economics, social epidemiology, and public health (work package members from our project (SOPHIE project, 2014)) and one meeting with two experts from the field of alcohol addiction. During these meetings we presented initial drafts of our framework, to which we received comments from the experts. These comments were used to refine and complete the framework on how economic crises may exert an effect on alcohol consumption and alcohol-related health problems. According to our theoretical framework, five different mechanisms may play a role at the individual level (M1 to M5 inFig. 1 and Table 1). Different mechanisms may play a role in different countries (country-level context: economic, political, and societal determinants) and between different subgroups within a population (individual context).

\section{[FIGURE 1] [TABLE 1]}

\subsection{Searching for primary studies}

The systematic search strategy for this realist review was developed with input from a librarian, and was executed on May 1, 2014. We searched multiple databases: three health databases (MEDLINE, Web of Science, and Embase), two psychological/social databases (PsycINFO and Sociological Abstracts), and one economic database (EconLit). We used synonyms for the determinant "economic crisis" and for the outcomes "alcohol consumption" and "alcohol-related health problems" (Table 2). The search was restricted to papers written in English, whereas no restrictions were applied to the type of publication. Papers published before 1990 (or which described a crisis that took place before 1990) were excluded, as there appeared to be little peer-reviewed empirical evidence available on the impact of economic crises before this date.

\section{[TABLE 2]}

\subsection{Selecting studies and appraising study quality}

All titles and abstracts were scored by the first reviewer (MCMdG) to identify full text papers that were relevant for our realist systematic review. This scoring applied three criteria: 1) the title/abstract indicates an economic crisis as a determinant or context, 2) the title/abstract indicates alcohol consumption or alcohol-related health problems as an outcome, and 3) the title/abstract describes a peer-reviewed empirical research method. The latter criterion excluded commentaries, replies, letters, and discussions of books and theses. Papers that met all three criteria were included for further selection. When two of the three criteria were met, the abstract was also scored by a second reviewer (AEK). Selection of full text papers (MCMdG) was based on four additional criteria: 1) availability of full text (thus excluding conference abstracts), 2) inclusion of an adult ( $\geq 18$ years) study population, 3 ) focus on an economic crisis after 1990, and 4) provision of empirical evidence on one or 
Goeij, de M.C.M., Suhrcke, M., Toffolutti, V., Mheen, D. van de, Schoenmakers, T.M., Kunst, A.En How economic crises affect alcohol consumption and alcohol-related health problems: a realist systematic review. Social Science \& Medicine: 2015, 131(1), 131-146

more mechanisms by which economic crises possibly exert an effect on alcohol consumption and alcohol-related health problems.

Full text papers meeting all of the criteria were assessed for scientific quality. These criteria were derived from the quality checklist developed by Spencer et al.

(2003) for qualitative research and the Strengthening the Reporting of Observational Studies in Epidemiology (STROBE) quality checklist (von Elm et al., 2007) for quantitative research. Scientific quality was scored by two reviewers (MCMdG and BvdW). We focused on a clear description of the following elements: 1) research question, 2) study population, 3) collection procedures, and 4) analytical methods. When the study quality was satisfactory in all of these respects, the full text paper was included for data extraction, appraisal, and synthesis.

\subsection{Extracting, analyzing, and synthesizing relevant data}

We extracted information on title, authors, journal, year, study population, study design, country-level context, mechanism, determinant, outcome, individual context, results, and additional literature from the included full text papers

(Appendix: Table 1).

Two reviewers (MCMdG and BvdW) independently appraised the degree of coverage of the evidence for each extracted mechanism. It was possible to extract multiple mechanisms from a single paper. We did not appraise the degree of coverage of all of the evidence reported in a paper, but only the evidence that supported or rejected that specific mechanism. We appraised the degree of coverage for two characteristics: 1) the detail in which the extracted mechanism was described in the paper, and 2) the degree to which this description was based on new evidence that was generated by the study itself. The level of detail of the mechanism descriptions was classified as either "thick" (individual economic and social situation, intermediate steps (e.g., psychological distress), and type of alcohol-related outcome were described) or "thin" (one element of the mechanism was not described). Coverage of empirical evidence was classified as "broad" when it could support or reject the entire mechanism. The coverage was "moderate" when empirical evidence described only a part of the mechanism. So, moderate classified evidence provided evidence only for the effect of economic crises on behavioral changes, or of behavioral changes on alcohol-related outcomes. Coverage of empirical evidence was classified as "small" when no evidence was given on intermediate mechanisms or when new empirical evidence was not generated by the study itself (authors refer to evidence from other studies or only speculate). Studies with small classified evidence were excluded from the results section (Appendix: Table 1).

Context-mechanism-outcome (CMO) configurations were annotated and extracted from all of the included full text papers. CMO configurations describe how a mechanism $(\mathrm{M})$ leads to an outcome $(\mathrm{O})$ within specific contexts and/or subgroups within a population $(\mathrm{C})$. CMO configurations were the basis for refining the initial theoretical framework of this review (Pawson, 2006). An example of a CMO configuration is that income reductions $(\mathrm{M})$ caused by the "Great Recession" in the US (C) reduced the consumption of alcoholic beverages $(\mathrm{O})$, but only in middle-aged men $(\mathrm{C})$. The extracted CMO configurations were then clustered in accordance with our initial theoretical framework. In the example above, this CMO was included in the cluster relevant to M3 of our framework (Fig. 1). 
Goeij, de M.C.M., Suhrcke, M., Toffolutti, V., Mheen, D. van de, Schoenmakers, T.M., Kunst, A.Ef How economic crises affect alcohol consumption and alcohol-related health problems: a realist systematic review. Social Science \& Medicine: 2015, 131(1), 131-146

\section{RESULTS}

\subsection{Selection of papers}

The flow diagram in Fig. 2 shows the selection of full text papers. Of the 87 included full text papers, 45 were excluded based on the defined criteria. Five additional full text papers were included after checking the references cited in the included papers. Twelve out of the 47 included studies provided only small evidence for a mechanism, and were therefore excluded from our results section. Study characteristics are presented in Table 1 (Appendix); the studies shaded in gray were not included in our results section. Table 3 gives the number of studies providing evidence to support or reject each of the five mechanisms, and how many of these studies provided a thick description of the mechanism, how many of these provided evidence with a broad coverage, and how many had a longitudinal design.

\section{[FIGURE 2] [TABLE 3]}

\subsection{Mechanisms 1 and 2: increased psychological distress}

\subsubsection{Mechanism}

Economic stressors can cause psychological distress, including depression, anxiety, irritability, denial, and anger. Psychological distress is related to higher frequencies and volumes of alcohol consumption and to a higher prevalence of problem drinking (e.g., alcohol dependence, intoxication, and negative consequences) (Blau et al., 2013,Brown and Richman, 2012, Cockerham et al., 2006, Hraba et al., 2000, Kalousova and Burgard, 2014 and Vijayasiri et al., 2012). Stressors related to work situation (e.g., underemployment, and wage reductions), unemployment, and income can cause psychological distress. During the Czech transformation, frustration at not having enough money led to irritability and thereby more drinking problems (Hraba et al., 2000). During the post-2007 Great Recession in the US, economic stressors led to an increased frequency and volume of drinking and problem drinking through psychological distress (i.e., depression, denial, anger, and anxiety) (Blau et al., 2013,Brown and Richman, 2012 and Kalousova and Burgard, 2014) and through somatic symptoms (e.g., sleep problems, stomach problems, migraines, and fatigue) (Vijayasiri et al., 2012). Somatic symptoms and psychological distress often occur together (Haug et al., 2004). During the economic and social transition in Eastern Europe, psychological symptoms (e.g., being stressed, feeling lonely, and losing confidence) and somatic symptoms (e.g., insomnia, trembling, and fatigue) were associated with a higher prevalence of frequent drinking (4-6 times per week or daily) (Cockerham et al., 2006). Moreover, during the Russian transition, economic difficulties and deterioration in material well-being coincided with poor self-rated health (Carlson, 2001), and poor self-rated health was associated with more heavy drinking $(\geq 0.25 \mathrm{~L}$ of vodka on a single occasion at least once a month) (Bobak et al., 1999). In contrast, during the post2008 economic crisis in Iceland, heavy drinking ( $\geq 5$ drinks on 1 day at least once a month) decreased and remained so after controlling for anxiety and poor mental health (Asgeirsdottir et al., 2014). This shows that psychological distress remained relatively unaffected in Iceland.

Unemployment seems to be one of the most important economic stressors. A repeated cross-sectional study by Gili et al. showed that, with regard to the post-2008 
Goeij, de M.C.M., Suhrcke, M., Toffolutti, V., Mheen, D. van de, Schoenmakers, T.M., Kunst, A.Ef How economic crises affect alcohol consumption and alcohol-related health problems: a realist systematic review. Social Science \& Medicine: 2015, 131(1), 131-146

economic crisis in Spain, almost one-third of the impact this had on mental health disorders (including alcohol dependence and abuse) could be explained by a rise in unemployment (Gili et al., 2013). Three further studies mentioned that psychological distress in unemployed people accumulated over time (Blau et al., 2013, Frijters et al., 2013 and Garcy and Vagero, 2012). A longer duration of unemployment was correlated with greater levels of denial, anger, and depression in the US (Blau et al., 2013). Garcy et al. showed that, after becoming unemployed, the risk for alcoholrelated mortality increased over time during the crisis in Sweden in the early 1990s (Garcy and Vagero, 2012). Moreover, Google searches using "alcohol" (as a proxy for alcohol-related problems) started to increase 6-9 months after unemployment rates rose as a consequence of the Great Recession in the US (Frijters et al., 2013). This time lag of 6-9 months could indicate that psychological distress had accumulated over time.

At country level, it seems that the impact of unemployment on alcohol consumption and alcohol-related health problems is greater during economic crises. One repeated cross-sectional study showed that the association between unemployment and alcohol dependence and abuse was stronger during the post-2008 economic crisis in Spain than it had been before the crisis (Gili et al., 2013). The study by Herzfeld et al. (2014), showed that during the Russian transition, unemployment at the macro level was an important stressor, as alcohol consumption (in grams of pure alcohol per day) was higher in areas with high unemployment rates, among both employed and unemployed people. Opposite associations between unemployment rate and number of drinks and heavy drinking were shown in the US by Nandi et al. (2013).

\subsubsection{Context}

Evidence provided by studies that investigated the post-2007 Great Recession in the US and the Russian transition indicates that men seem to use drinking as a stressreleasing coping strategy more often than women. This evidence covered the entire mechanism. During the Great Recession in the US, the association between depression and anxiety and alcohol dependence was stronger in men than in women (Brown and Richman, 2012). Furthermore, somatic symptoms were associated with problem drinking among men, but not among women (Vijayasiri et al., 2012). During the transition in Eastern Europe, psychological symptoms, somatic symptoms, and poor self-rated health were related to more frequent and heavy drinking among men, but not among women (Bobak et al., 1999 and Cockerham et al., 2006). In line with this, during the crisis in Sweden and Finland in the early 1990s, the Russian transition, and the Great Recession in the US, it was predominately in men that economic stressors led to more drinks, a higher frequency of drinking, more heavy drinking, more alcohol dependence, and more alcoholrelated mortality (Garcy and Vagero, 2012, Jukkala et al., 2008, Luoto et al., 1998, Mulia et al., 2014 and Richman et al., 2012). In addition, the impact of economic crises and unemployment on alcohol consumption and alcohol-related health problems was greatest among individuals aged 25-34 and 45-59 (Bor et al., 2013 and Luoto et al., 1998), those with low educational levels (Luoto et al., 1998 and Munne, 2005), single or divorced people (Luoto et al., 1998), and black people (Lo and Cheng, 2013 and Zemore et al., 2013). 
Goeij, de M.C.M., Suhrcke, M., Toffolutti, V., Mheen, D. van de, Schoenmakers, T.M., Kunst, A.En How economic crises affect alcohol consumption and alcohol-related health problems: a realist systematic review. Social Science \& Medicine: 2015, 131(1), 131-146

\subsection{Mechanism 3: tighter budget constraints}

\subsubsection{Mechanism}

Tighter budget constraints during an economic crisis due to income reductions (Carlson and Vagero, 1998, Chalmers and Ritter, 2011, Garcy and Vagero, 2012,Johansson et al., 2006, Karlsson et al., 2010, Lai and Habicht, 2011, Munne, 2005,Perlman, 2010 and Tangcharoensathien et al., 2000) or price increases (Asgeirsdottir et al., 2014, Barda and Sardianou, 2010, Doran and Digiusto, 2011 and Treisman, 2010) can lead to less money being spent on alcoholic beverages and thereby less alcohol consumption (including liters per capita, number of drinks consumed, frequent drinking, and heavy drinking (Asgeirsdottir et al., 2014, Barda and Sardianou, 2010,Carlson and Vagero, 1998, Chalmers and Ritter, 2011, Johansson et al., 2006, Lai and Habicht, 2011, Munne, 2005 and Tangcharoensathien et al., 2000)). As a result, this could affect alcoholrelated mortality at the population level (Garcy and Vagero, 2012 and Treisman, 2010). Four studies showed that income reductions could not "entirely" explain the observed decreases in alcohol consumption and alcohol-related mortality. During (but not before) the crisis in Finland in the early 1990s, lower regional GDP growth was correlated with lower alcohol-related mortality (Johansson et al., 2006). The study by Asgeirsdottir et al. (2014), showed that the decrease in heavy drinking during the post-2008 economic crisis in Iceland could not be completely explained by household income reductions, loss of financial assets, or increased mortgage debt. Two other studies that investigated the post-2007 Great Recession in the US showed that reductions in alcohol consumption (quantity and frequency) could not be explained by household income reductions (Bor et al., 2013), and that these reductions occurred among both unemployed and employed people (Nandi et al., 2013). Three additional studies showed absent or contradictory associations between job loss or lost resources and harmful drinking (Kalousova and Burgard, 2014, Lo and Cheng, 2013 and Zemore et al., 2013).

The other defined strategies for adjusting to tighter budget constraints are switching to cheaper alcoholic beverages (e.g., switching from liquor to wine, or from purchased alcoholic beverages to low-quality home-distilled ones) (Doran and Digiusto, 2011,Karlsson et al., 2010, Munne, 2005 and Perlman, 2010) or substituting drinking in bars with drinking at home (Munne, 2005). In Finland and Australia, the consumption of distilled spirits (pure or ready to drink) decreased during crises, but wine, beer, and cider consumption increased (Doran and Digiusto, 2011 and Karlsson et al., 2010). In Russia, people switched to home-distilled alcoholic beverages such as samogon (Perlman, 2010). During the economic crisis in Argentina in the late $1990 \mathrm{~s}$, approximately $75 \%$ of the study population mentioned that they knew people who had stopped going to bars and instead drank at their own home or at a friend's home (Munne, 2005).

\subsubsection{Context}

In Argentina, mainly women and people with low educational levels agreed that it is important to cut down on expenses for alcohol during economic crises (Munne, 2005). It was only during the transition in Russia that men and women turned to lowquality home-distilled alcohol (Perlman, 2010). The Russian men who switched to these low-quality alcoholic beverages were mainly 60 years of age or older, lived in 
Goeij, de M.C.M., Suhrcke, M., Toffolutti, V., Mheen, D. van de, Schoenmakers, T.M., Kunst, A.En How economic crises affect alcohol consumption and alcohol-related health problems: a realist systematic review. Social Science \& Medicine: 2015, 131(1), 131-146

rural areas, were pessimistic about their financial situation, and were heavy drinkers. In contrast, Koreans continued to drink as a leisure activity during the crisis in 1997, while they reduced other everyday expenditures (Mun-Kyum, 2005).

\subsection{Mechanism 4: deterioration in the social situation}

\subsubsection{Mechanism}

During the recent Great Recession in the US (post-2007), a change in a person's social position, such as divorce or increased social isolation, was moderately associated with more drinks consumed and strongly associated with problem drinking (i.e., drinking to intoxication, binge drinking, and past-year alcohol dependence) (Richman et al., 2012). Four other studies from the US, Albania, Russia, and Australia also showed that social isolation, change in social order or role, and loss of social status were related to more drinking (Burazeri and Kark, 2010, Jukkala et al., 2008 and Kalousova and Burgard, 2014; Taylor et al., 2010).

\subsubsection{Context}

During the Great Recession in the US, a change in a person's social position increased the prevalence of problem drinking; this was stronger in men than in women (Richman et al., 2012). During the transition in Albania, men with a low subjectively assessed social position were more often binge drinkers (this was not investigated in women) (Burazeri and Kark, 2010). During the transition in Russia, the association between economic problems (including forgoing social or cultural activities) and binge drinking was present in men and absent in women (most absent in married women) (Jukkala et al., 2008). During the global financial crisis in Australia, men more often reported drinking as a coping mechanism than women; women reported that family, friends, and faith helped them through tough times (Taylor et al., 2010). Based on these findings, the authors hypothesized that men are more susceptible to adverse health responses resulting from unemployment and income reductions because they can no longer fulfill their culturally defined role of family protector and provider.

\subsection{Mechanism 5: more non-working time}

We found no evidence to support the expectation that changes in non-working time during economic crises affect health behaviors such as drinking. Two studies provided evidence on the impact of reduced hours of "paid" work - and thus more non-working time - on alcohol consumption and alcohol-related health problems. Reduced hours of paid work did not mediate the impact of the Icelandic post-2008 economic crisis on the reduction in heavy drinking (Asgeirsdottir et al., 2014). During the post-2007 Great Recession in the US, reduced hours of paid work was associated with more negative drinking consequences and alcohol dependence (Mulia et al., 2014).

\subsection{Additional mechanisms: increased responsibility and less work-related stress}

Several studies described two other mechanisms (which we did not include in our initial theoretical framework). According to the first mechanism, during economic crises, employed people consume fewer drinks and drink less heavily to increase their chances of holding on to their job, and unemployed people lower their consumption to increase their chances of getting a new job (Chalmers and Ritter, 
Goeij, de M.C.M., Suhrcke, M., Toffolutti, V., Mheen, D. van de, Schoenmakers, T.M., Kunst, A.En How economic crises affect alcohol consumption and alcohol-related health problems: a realist systematic review. Social Science \& Medicine: 2015, 131(1), 131-146

2011, Shim and Cho, 2013 and Zemore et al., 2013). According to the second mechanism, a lighter workload during a crisis may lead to less stress and thereby to a reduction in alcohol consumption (Frijters et al., 2013 and Johansson et al., 2006). However, neither mechanism was supported by evidence. The only evidence that could be extracted from the included studies was on the impact of crises or unemployment on alcohol-related outcomes.

\section{DISCUSSION}

\subsection{Refining the initial theoretical framework and the strength of evidence}

Our realist systematic review has found strong empirical evidence on several crises across many countries to support two behavioral mechanisms by which economic crises may exert an effect on alcohol consumption and alcohol-related health problems. These behavioral mechanisms are increased psychological distress and tighter budget constraints.

According to the first mechanism, people may drink more when they feel anxious, depressed, and frustrated. These presentations of psychological distress can be triggered by unemployment, income reductions, or altered work situations (e.g., underemployment, and lower wages). Drinking as a coping mechanism to relieve distress was observed predominately in men, and much less so in women. In addition, evidence showed that distress in men primarily increased harmful drinking, including alcohol dependence, negative consequences of drinking, binge drinking, hazardous drinking, and intoxication. This is in line with the "self-medication theory", which suggests that drinking to cope with stressful situations may increase alcohol dependence in certain people (Bolton et al., 2009 and Khantzian, 1997). The second mechanism that is often used is to spend less money on alcoholic beverages during times of financial hardship. The evidence indicates that this mechanism is used by people across all countries and in nearly all subgroups within a population. This is in line with the basic theory of economics that individual budget constraints will result in less money being spent on normal goods ("income-effect theory") (Catalano, 1997 and Ruhm, 1995). More specifically, the evidence mainly showed a reduction in the volume of alcohol consumption and number of drinks rather than a reduction in heavy and problematic drinking.

Unfortunately, there was no strong evidence to support the other three behavioral mechanisms described in our initial theoretical framework - deterioration in the social situation, fear of losing one's job, and increased non-working time - but only evidence with moderate coverage. This was also the case for potentially influential contextual factors (e.g., age, education, and marital status). Therefore, less weight can be given to this evidence.

\subsection{Limitations of the included studies}

In many of the included studies, the descriptions provided for how economic crises may affect alcohol consumption and alcohol-related health problems at the individual level were classified as thick. However, we found strong supporting evidence only for the mechanisms psychological distress (mainly in men) and tighter budget constraints. For the psychological distress mechanism, evidence supported the entire mechanism, from individual economic changes to psychological distress, and from psychological distress to alcohol-related outcomes. However, little evidence was extracted from studies that included longitudinal individual level data. This reduces 
Goeij, de M.C.M., Suhrcke, M., Toffolutti, V., Mheen, D. van de, Schoenmakers, T.M., Kunst, A.En How economic crises affect alcohol consumption and alcohol-related health problems: a realist systematic review. Social Science \& Medicine: 2015, 131(1), 131-146

the strength of the evidence on causal relationships underlying these two reported mechanisms. As for the association between psychological distress and alcohol consumption, individuals who consume large amounts of alcohol might also become more distressed.

As mentioned previously, there was no empirical evidence for three other behavioral mechanisms, that is fear of losing one's job, responsibility for holding on to their job or getting a new job, and less work-related stress. Evidence had moderate coverage for potentially influential contextual factors (e.g., age, education, and marital status) and for the behavioral mechanisms of deterioration in the social situation and increased non-working time. This moderate evidence could not support the entire mechanism, from the crisis or economic stressors to deterioration in the social situation or increased non-working time, followed by changes in alcohol-related outcomes.

\subsection{Limitations of our realist systematic review}

The explanatory evidence of our realist systematic review can help to determine which policies can best be implemented in times of economic crises, and to formulate hypotheses for further research. However, a limitation of the realist evaluation methodology is that the process of finding, extracting, analyzing, and synthesizing evidence cannot be pre-structured to the same extent as traditional approaches and that therefore the outcomes may be more dependent on the choices that authors make.

For example, we excluded studies that investigated the impact of unemployment, income reductions, and price increases on alcohol consumption and alcohol-related health problems outside the context of an economic crisis. We did so because when a crisis occurs, this can influence the impact of economic stressors on alcohol consumption. Several studies showed that during a crisis, economic stressors had a stronger impact on alcohol-related outcomes than before the crisis (Gili et al., 2013,Harhay et al., 2013 and Johansson et al., 2006). A limitation of this restriction is that we may have missed descriptions of how economic stressors might affect alcohol consumption and alcohol-related health problems, or relevant cited references. Another choice that could have influenced our review is that only papers written in English were included, which might have led to information bias.

\subsection{Implications}

The post-2008 economic crisis in Europe is characterized by rising unemployment rates and tighter budget constraints. Some countries have been adopting austerity measures (Karanikolos et al., 2013), which can aggravate or alleviate financial strain among individuals. It is hard to establish what the overall net impact of the post-2008 economic crisis is on trends in alcohol consumption at the population level. Moreover, our review showed that two contradictory mechanisms come into play during such difficult times. In Iceland (Asgeirsdottir et al., 2014), heavy drinking decreased after the start of the crisis, while in Spain (Gili et al., 2013), alcohol abuse and dependence increased. Initial results from Europe presented in a World Health Organization (WHO) report (Shield et al., 2013) suggest no trend changes in alcohol consumption between 2008 and 2010.

The impact of the post-2008 and other economic crises could also differ between subgroups within a country. Austerity measures - such as budget cuts to social welfare and healthcare - mainly affect people with a low income and a low 
Goeij, de M.C.M., Suhrcke, M., Toffolutti, V., Mheen, D. van de, Schoenmakers, T.M., Kunst, A.En How economic crises affect alcohol consumption and alcohol-related health problems: a realist systematic review. Social Science \& Medicine: 2015, 131(1), 131-146

educational level. The combination of low income and less financial support may dramatically increase psychological distress in lower socioeconomic groups. The evidence presented in this review indicates that, in addition to men, those with low educational levels and single or divorced people are also more likely to use drinking as a coping mechanism to deal with stress. In accordance with the "self-medication theory" (Bolton et al., 2009,Carrigan and Randall, 2003, Khantzian, 1985 and Khantzian, 1997), drinking to cope with stressful situations can lead to harmful drinking and alcohol dependence. Therefore, this may have resulted in a substantial increase in alcohol-related health problems among the aforementioned specific subgroups within a population. Although according to the "income-effect theory" alcohol consumption may decrease in the population as a whole, these differential effects between subgroups may contribute to growing health inequalities during an economic crisis.

\subsection{Future research}

Based on this realist systematic review, we formulate three recommendations for future research. First, data should come from individual-level longitudinal studies that specifically aim to investigate which mechanisms play a role in which subgroups within a population. Evidence from longitudinal studies supporting all subsequent steps of the mechanisms described in our initial framework is scarce and the evidence that is available did not always focus on possible differences between subgroups. Second, in line with our first recommendation, it is very important to carry out international comparative studies. In our review, we could not locate any study that compared mechanisms between countries. Such evidence can be used to better understand and/or assess the possible impact of the European post-2008 economic crisis (but also other crises) on Europe as a whole and on individual countries. Third, it is important to investigate whether the impact of the post-2008 or other economic crises on alcohol consumption and alcohol-related health problems vary between socioeconomic groups because our results indicated such differential effects.

\section{CONCLUSION}

More evidence is needed on how economic crises may exert an effect on alcoholrelated outcomes. Although, we can conclude from this realist review that two opposing mechanisms may come into play during a crisis: reductions in alcohol consumption due to tighter budget constraints and a rise in harmful drinking due to increased psychological distress. The net impact among men seems to be an increase in levels of harmful drinking and in the incidence of alcohol-related health problems, possibly contributing to growing gender-related health inequalities during economic crises.

\section{ACKNOWLEDGMENTS}

The authors gratefully acknowledge Bregje van der Wouden for reviewing the quality of the included studies and coverage of evidence for the extracted mechanisms. This research was part of the SOPHIE project, which received funding from the European Community's Seventh Framework Programme (FP7/2007-2013) under grant agreement number 278173. 
Goeij, de M.C.M., Suhrcke, M., Toffolutti, V., Mheen, D. van de, Schoenmakers, T.M., Kunst, A.En How economic crises affect alcohol consumption and alcohol-related health problems: a realist systematic review. Social Science \& Medicine: 2015, 131(1), 131-146

\section{REFERENCES}

Anderson, P., Chisholm, D., Fuhr, D.C., 2009. Effectiveness and cost-effectiveness of policies and programmes to reduce the harm caused by alcohol. Lancet 373 (9682), $2234 \mathrm{e} 2246$.

Asgeirsdottir, T.L., Corman, H., Noonan, K., Olafsdottir, T., Reichman, N.E., 2014. Was the economic crisis of 2008 good for Icelanders? Impact on health behaviors.

Econ. Hum. Biol. 13, 1e19.

Baker, T.D.B., 2011. Trauma in the Russian Federation: then and now. J. Trauma Inj. Infect. Crit. Care 70 (4), 991e995.

Barda, C., Sardianou, E., 2010. Analysing consumers' 'activism' in response to rising prices. Int. J. Consum. Stud. 34 (2), 133e139.

Bhattacharya, J., Gathmann, C., Miller, G., 2013. The Gorbachev anti-alcohol campaign and Russia's mortality crisis. Am. Econ. J. Appl. Econ. 5 (2), 232e260.

Blanchard, O., Amighini, A., Giavazzi, F., 2010. Macroeconomics: a European Perspective Macroeconomics: a European Perspective. Pearson Education Limited, England.

Blau, G., Petrucci, T., McClendon, J., 2013. Exploring the impact of situational background, emotional, and job search variables on coping with unemployment by drinking versus considering self-employment. J.Workplace Behav. Health 28 (3), $212 \mathrm{e} 233$.

Bobak, M., McKee, M., Rose, R., Marmot, M., 1999. Alcohol consumption in a national sample of the Russian population. Addiction 94 (6), 857e866.

Bolton, J.M., Robinson, J., Sareen, J., 2009. Self-medication of mood disorders with alcohol and drugs in the national epidemiologic survey on alcohol and related conditions. J. Affect Disord. 115 (3), 367e375.

Bor, J., Basu, S., Coutts, A., McKee, M., Stuckler, D., 2013. Alcohol use during the Great Recession of 2008-2009. Alcohol Alcohol 48 (3), 343e348.

Brown, R.L., Richman, J.A., 2012. Sex differences in mediating and moderating processes linking economic stressors, psychological distress, and drinking.

J. Stud. Alcohol Drugs 73 (5), 811e819.

Burazeri, G., Kark, J.D., 2010. Prevalence and determinants of binge drinking in middle age in a transitional post-communist country: a population-based study in Tirana, Albania.

Alcohol Alcohol 45 (2), 180e187.

Carlson, P., 2001. Risk behaviours and self rated health in Russia 1998. J. Epidemiol.

Community Health 55 (11), 806e817.

Carlson, P., Vagero, D., 1998. The social pattern of heavy drinking in Russia during

transition: evidence from Taganrog 1993. Eur. J. Public Health 8 (4), $280 \mathrm{e} 285$.

Carrigan, M.H., Randall, C.L., 2003. Self-medication in social phobia: a review of the alcohol literature. Addict. Behav. 28 (2), $269 \mathrm{e} 284$.

Catalano, R., 1997. An emerging theory of the effect of economic contraction on alcohol abuse in the United States. Soc. Justice Res. 10 (2), 191e201.

Chalmers, J., Ritter, A., 2011. The business cycle and drug use inAustralia: evidence from repeated cross-sections of individual level data. Int. J. Drug Policy 22 (5), 341e352.

Chang, S.S., Gunnell, D., Sterne, J.A.C., Luc, T.H., Cheng, A.T.A., 2009. Was the economic crisis 1997-1998 responsible for rising suicide rates in East/Southeast Asia? A time-trend analysis for Japan, Hong Kong, South Korea, Taiwan, Singapore and Thailand. Soc. Sci. Med. 68 (7), 1322e1331.

Cockerham, W.C., Hinote, B.P., Abbott, P., 2006. Psychological distress, gender, and health lifestyles in Belarus, Kazakhstan, Russia, and Ukraine. Soc. Sci. Med. 63 (9), 2381e2394.

Doran, C.M., Digiusto, E., 2011. Using taxes to curb drinking: a report card on the Australian government's alcopops tax. Drug Alcohol Rev. 30 (6), 677e680.

Eurostat, 2012. Eurostat Statistics Database. http://epp.eurostat.ec.europa.eu/portal/ page/portal/statistics/search_database.

French, M.T., Popovici, I., Maclean, J.C., 2009. Do alcohol consumers exercise more? Findings from a national survey. Am. J. Health Promot 24 (1), 2e10.

Frijters, P., Johnston, D.W., Lordan, G., Shields, M.A., 2013. Exploring the relationship between macroeconomic conditions and problem drinking as captured by Google searches in the US. Soc. Sci. Med. 84, 61e68. 
Goeij, de M.C.M., Suhrcke, M., Toffolutti, V., Mheen, D. van de, Schoenmakers, T.M., Kunst, A.En How economic crises affect alcohol consumption and alcohol-related health problems: a realist systematic review. Social Science \& Medicine: 2015, 131(1), 131-146

Garcy, A.M., Vagero, D., 2012. The length of unemployment predicts mortality, differently in men and women, and by cause of death: a six year mortality follow-up of the Swedish 1992-1996 recession. Soc. Sci. Med. 74 (12), 1911e1920.

Gili, M., Roca, M., Basu, S., McKee, M., Stuckler, D., 2013. The mental health risks of economic crisis in Spain: evidence from primary care centres, 2006 and 2010.

Eur. J. Public Health 23 (1), 103e108.

Harhay, M.O., Bor, J., Basu, S., McKee, M., Mindell, J.S., Shelton, N.J., Stuckler, D., 2013.

Differential impact of the economic recession on alcohol use among white British adults, 2004-2010. Eur. J. Public Health 24 (3), 410e415.

Haug, T.T., Mykletun, A., Dahl, A.A., 2004. The association between anxiety, depression, and somatic symptoms in a large population: the HUNT-II study.

Psychosom. Med. 66 (6), 845e851.

Herttua, K., Makela, P., Martikainen, P., 2007. Differential trends in alcohol-related mortality: a register-based follow-up study in Finland in 1987-2003. Alcohol Alcohol 42 (5), 456e464.

Herzfeld, T., Huffman, S., Rizov, M., 2014. The dynamics of food, alcohol and cigarette consumption in Russia during transition. Econ. Hum. Biol. 13 (1), 128e143.

Hintikka, J., Saarinen, P.I., Viinamaki, H., 1999. Suicide mortality in Finland during an economic cycle, 1985-1995. Scand. J. Public Health 27 (2), 85e88.

Hraba, J., Lorenz, F.O., Pechacova, Z., 2000. Family stress during the Czech transformation.

J. Marriage Fam. 62 (2), 520e531.

Hyypp€a, M.T., Kronholm, E., Alanen, E., 1997. Quality of sleep during economic recession in Finland: a longitudinal cohort study. Soc. Sci. Med. 45 (5), 731e738.

Johansson, E., Bockerman, P., Prattala, R., Uutela, A., 2006. Alcohol-related mortality, drinking behavior, and business cycles: are slumps really dry seasons? Eur. J.

Health Econ. 7 (3), 215e220.

Jukkala, T., Makinen, I.H., Kislitsyna, O., Ferlander, S., Vagero, D., 2008. Economic strain, social relations, gender, and binge drinking in Moscow. Soc. Sci. Med. 66 (3), 663e674.

Kalousova, L., Burgard, S.A., 2014. Unemployment, measured and perceived decline of economic resources: contrasting three measures of recessionary hardships and their implications for adopting negative health behaviors. Soc. Sci. Med.

$106,28 \mathrm{e} 34$.

Karanikolos, M., Mladovsky, P., Cylus, J., Thomson, S., Basu, S., Stuckler, D., , et al.McKee, M., 2013. Financial crisis, austerity, and health in Europe. Lancet 381 (9874), 1323e1331.

Karlsson, T., Makela, P., Osterberg, E., Tigerstedt, C., 2010. A new alcohol environment: trends in alcohol consumption, harms and policy: Finland 1990e2010.

NAT Nord. alkohol nark. 27 (5), 497e513.

Khantzian, E.J., 1985. The self-medication hypothesis of addictive disorders: focus on heroin and cocaine dependence. Am. J. Psychiatry 142 (11), 1259e1264.

Khantzian, E.J., 1997. The self-medication hypothesis of substance use disorders: a reconsideration and recent applications. Harv. Rev. Psychiatry 4 (5), 231e244.

Lai, T., Habicht, J., 2011. Decline in alcohol consumption in Estonia: combined effects of strengthened alcohol policy and economic downturn. Alcohol Alcohol 46 (2), 200e203.

Lo, C.C., Cheng, T.C., 2013. Heavy drinking during periods of high unemployment: 15-year trend study of the role of race/ethnicity. Drug Alcohol Depend. 133 (2), 383e390.

Luoto, R., Poikolainen, K., Uutela, A., 1998. Unemployment, sociodemographic background and consumption of alcohol before and during the economic recession of the 1990s in Finland. Int. J. Epidemiol. 27 (4), $623 e 629$.

M€akel€a, P., 1999. Alcohol-related mortality during an economic boom and recession, Contemp. Drug Problems 26, 369e390.

Men, T., Brennan, P., Boffetta, P., Zaridze, D., 2003. Russian mortality trends for 19912001: analysis by cause and region. Br. Med. J. 327 (7421), 964.

Morris, E.P., Stewart, S.H., Ham, L.S., 2005. The relationship between social anxiety disorder and alcohol use disorders: a critical review. Clin. Psychol. Rev. 25 (6), 734e760.

Mulia, N., Zemore, S.E., Murphy, R., Liu, H., Catalano, R., 2014. Economic loss and alcohol consumption and problems during the 2008 to 2009 U.S. Recession.

Alcohol. Clin. Exp. Res. 38 (4), $1026 e 1034$. 
Goeij, de M.C.M., Suhrcke, M., Toffolutti, V., Mheen, D. van de, Schoenmakers, T.M., Kunst, A.En How economic crises affect alcohol consumption and alcohol-related health problems: a realist systematic review. Social Science \& Medicine: 2015, 131(1), 131-146

Mun-Kyum, K., 2005. The 1997 financial crisis and changing patterns of consumption and leisure in Korea. Korea J. 45 (3), 58e85.

Munne, M.I., 2005. Alcohol and the economic crisis in Argentina: recent findings.

Addiction 100 (12), 1790e1799.

Nandi, A., Charters, T.J., Strumpf, E.C., Heymann, J., Harper, S., 2013. Economic conditions and health behaviours during the 'Great Recession'. J. Epidemiol.

Community Health 0, 1 e9.

Obstfeld, M., Rogoff, K. Global Imbalances and the Financial Crisis: Products of Common Causes.

Pawson, R., 2006. Evidence-based Policy: a Realist Perspective. SAGE Publications Ltd, London.

Perlman, F.J.A., 2010. Drinking in transition: trends in alcohol consumption in Russia 19942004. BMC Public Health 10 (691), 1e13.

Rechel, B., Roberts, B., Richardson, E., Shishkin, S., Shkolnikov, V.M., Leon, D.A., , et al.McKee, M., 2013. Health and health systems in the Commonwealth of Independent States. Lancet 381 (9872), 1145e1155.

Rehm, J., Room, R., Graham, K., Monteiro, M., Gmel, G., Sempos, C.T., 2003. The relationship of average volume of alcohol consumption and patterns of drinking to burden of disease: an overview. Addiction 98 (9), 1209e1228.

Rehm, J., Room, R., Taylor, B., 2008. Method for moderation: measuring lifetime risk of alcohol-attributable mortality as a basis for drinking guidelines. Int. J.

Methods Psychiatr. Res. 17 (3), 141e151.

Richman, J.A., Rospenda, K.M., Johnson, T.P., Cho, Y.I., Vijayasira, G., Cloninger, L., Wolff, J.M., 2012. Drinking in the age of the great recession. J. Addict. Dis. 31 (2), $158 \mathrm{e} 172$.

Ruhm, C.J., 1995. Economic conditions and alcohol problems. J. Health Econ. 14 (5), $583 \mathrm{e} 603$.

Sayette, M.A.,1999. Does drinking reduce stress? Alcohol Res. Health 23 (4), 250 e255.

Sher, K.J., Bartholow, B.D., Peuser, K., Erickson, D.J., Wood, M.D., 2007. Stressresponsedampening effects of alcohol: attention as a mediator and moderator.

J. Abnorm Psychol. 116 (2), 362e377.

Sher, K.J., Levenson, R.W., 1982. Risk for alcoholism and individual differences in the stress-response-dampening effect of alcohol. J. Abnorm Psychol. 91 (5), 350e367.

Shield, K.D., Rylett, M.J., Gmel, G., Rehm, J., Brummer, J., Moller, L., 2013. Status Report on Alcohol and Health in 35 European Countries. Ministry of Social Affairs and Health, Finland; World Health Organization (WHO), Denmark.

Shim, E., Cho, Y., 2013. Widening social disparities in alcohol-attributable deaths among Korean men aged 40-59 years during the transitional period of the economic crisis (19952005). Int. J. Public Health 58 (4), 521e527.

SOPHIE project, 2014, http://www.sophie-project.eu/.

Spencer, L., Ritchie, J., Lewis, J., Dillon, L., 2003. In: Research, N.C.F.S. (Ed.), Quality in Qualitative Evaluation: a Framework for Assessing Research Evidence. A Quality Framework. Cabinet Office: Government Chief Social Researcher's Office.

Stuckler, D., Basu, S., 2013. The Body Economic: Why Austerity Kills. Basic Books, New York.

Stuckler, D., Basu, S., Suhrcke, M., McKee, M., 2009a. The health implications of financial crisis: a review of the evidence. Ulst. Med. J. 78 (3), 142e145.

Stuckler, D., Basu, S., Suhrcke, M., Coutts, A., McKee, M., 2009b. The public health effect of economic crises and alternative policy responses in Europe: an empirical analysis. Lancet 374 (9686), 315e323.

Tangcharoensathien, V., Harnvoravongchai, P., Pitayarangsarit, S., Kasemsup, V., 2000. Health impacts of rapid economic changes in Thailand. Soc. Sci. Med. 51 (6), $789 \mathrm{e} 807$.

Taylor, B., Rehm, J., Room, R., Patra, J., Bondy, S., 2008. Determination of lifetime injury mortality risk in Canada in 2002 by drinking amount per occasion and number of occasions. Am. J. Epidemiol. 168 (10), 1119e1125.

Taylor, M., Barr, M., Stevens, G., Bryson-Taylor, D., Agho, K., Jacobs, J., Raphael, B., 2010. Psychosocial stress and strategies for managing adversity: measuring population resilience in New South Wales, Australia. Popul. Health Metrics 8 (28), 1 e9. 
Goeij, de M.C.M., Suhrcke, M., Toffolutti, V., Mheen, D. van de, Schoenmakers, T.M., Kunst, A.E⿸尸 How economic crises affect alcohol consumption and alcohol-related health problems: a realist systematic review. Social Science \& Medicine: 2015, 131(1), 131-146

Treisman, D., 2010. Death and prices. The political economy of Russia's alcohol crisis. Econ. Trans. 18 (2), $281 \mathrm{e} 331$.

Valkonen, T., Martikainen, P., Jalovaara, M., Koskinen, S., Martelin, T., Makela, P., 2000. Changes in socioeconomic inequalities in mortality during an economic boom and recession among middle-aged men and women in Finland. Eur. J.

Public Health 10 (4), 274e280.

van Amsterdam, J., van den Brink,W., 2013. The high harm score of alcohol. Time for drug policy to be revisited? J. Psychopharmacol. 27 (3), 248e255.

Vijayasiri, G., Richman, J.A., Rospenda, K.M., 2012. The Great Recession, somatic symptomatology and alcohol use and abuse. Addict. Behav. 37 (9), 1019e1024.

von Elm, E., Altman, D.G., Egger, M., Pocock, S.J., Gotzsche, P.C., Vandenbroucke, J.P., 2007. The Strengthening the Reporting of Observational Studies in Epidemiology (STROBE) statement: guidelines for reporting observational studies. PLoS Med. 4 (10), e296.

Wahlbeck, K., McDaid, D., 2012. Actions to alleviate the mental health impact of the economic crisis. World Psychiatry 11 (3), 139e145.

WHO, 2009. The Financial Crisis and Global Health: Background Paper for WHO High Level Consultation. World Health Organization, Geneva.

WHO, 2011. Impact of Economic Crises on Mental Health. World Health Organization, Copenhagen.

Wojtyniak, B., Moskalewicz, J., Stokwiszewski, J., Rabczenko, D., 2005. Genderspecific mortality associated with alcohol consumption in Poland in transition.

Addiction 100 (12), 1779e1789.

Wong, G., Greenhalgh, T., Westhorp, G., Buckingham, J., Pawson, R., 2013. RAMESES publication standards: realist syntheses. BMC Med. 11, 21.

Zemore, S.E., Mulia, N., Jones-Webb, R.J., Liu, H.G., Schmidt, L., 2013. The 2008-2009 recession and alcohol outcomes: differential exposure and vulnerability for Black and Latino populations. J. Stud. Alcohol Drugs 74 (1), 9e20. 
Goeij, de M.C.M., Suhrcke, M., Toffolutti, V., Mheen, D. van de, Schoenmakers, T.M., Kunst, A.En How economic crises affect alcohol consumption and alcohol-related health problems: a realist systematic review. Social Science \& Medicine: 2015, 131(1), 131-146

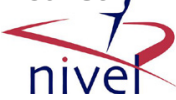

\section{TABLES AND FIGURES}

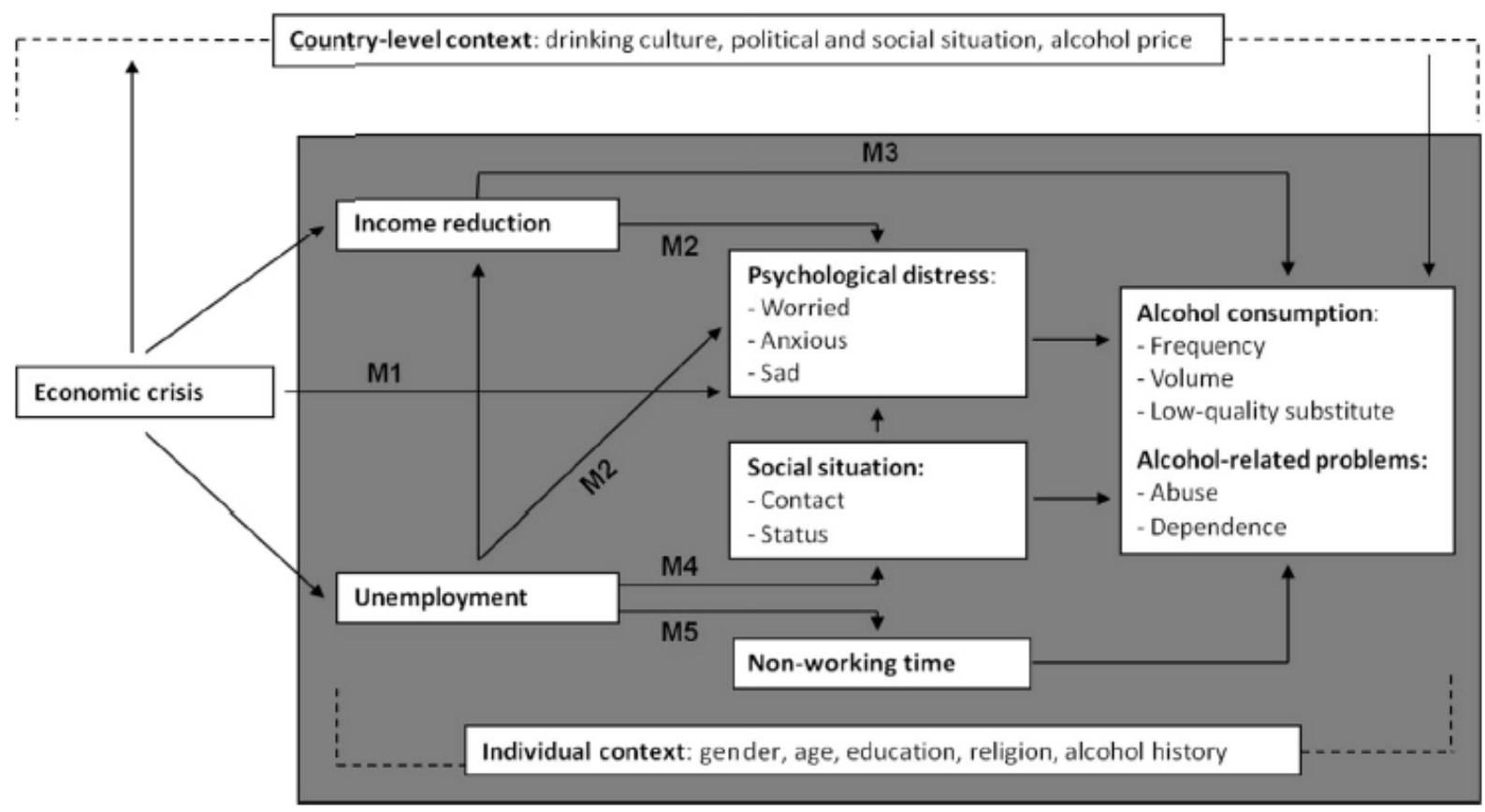

Fig. 1. Initial theoretical framework. 
Goeij, de M.C.M., Suhrcke, M., Toffolutti, V., Mheen, D. van de, Schoenmakers, T.M., Kunst, A.En How economic crises affect alcohol consumption and alcohol-related health problems: a realist systematic review. Social Science \& Medicine: 2015, 131(1), 131-146

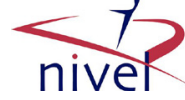

Table 1

Initial configuration of mechanisms.

\begin{tabular}{|c|c|c|}
\hline Context & Mechanism & Outcome \\
\hline $\begin{array}{l}\text { Country-level } \\
\text { context: } \\
\text { drinking } \\
\text { culture, } \\
\text { political and } \\
\text { social situation, } \\
\text { alcohol price }\end{array}$ & $\begin{array}{l}\text { M1 Fear of job loss or income } \\
\text { reductions increases psychological } \\
\text { distress (e.g., worried, anxious, sad). To } \\
\text { cope with these feelings, more alcohol } \\
\text { may be consumed and this may lead to } \\
\text { more alcohol-related health problems. }\end{array}$ & $\begin{array}{l}\text { Alcohol } \\
\text { consumption } \\
\text { and alcohol- } \\
\text { related health } \\
\text { problems }\end{array}$ \\
\hline $\begin{array}{l}\text { Individual } \\
\text { context: } \\
\text { gender, age, } \\
\text { education, } \\
\text { religion, } \\
\text { alcohol history }\end{array}$ & $\begin{array}{l}\text { M2 Actual job loss or income reductions } \\
\text { adversely affects psychological distress } \\
\text { (e.g., worried, anxious, sad). To cope } \\
\text { with these feelings, more alcohol may } \\
\text { be consumed and this may lead to more } \\
\text { alcohol-related health problems. } \\
\text { M3 Income reductions result in tighter } \\
\text { individual budget constraints. This may } \\
\text { lead to reduced spending on alcoholic } \\
\text { beverages, or switching to cheaper } \\
\text { ones. } \\
\text { M4 Job loss adversely affects social } \\
\text { situations (e.g., loss of social status, and } \\
\text { social exclusion). This may lead to } \\
\text { increases in alcohol consumption and } \\
\text { thereby more alcohol-related health } \\
\text { problems. } \\
\text { M5 Less working time and more non- } \\
\text { working time (either due to job loss or } \\
\text { fewer tasks at work) can increase the } \\
\text { frequency of unhealthy activities - } \\
\text { including alcohol consumption - both } \\
\text { positively and negatively. }\end{array}$ & \\
\hline
\end{tabular}


Goeij, de M.C.M., Suhrcke, M., Toffolutti, V., Mheen, D. van de, Schoenmakers, T.M., Kunst, A.En How economic crises affect alcohol consumption and alcohol-related health problems: a realist systematic review. Social Science \& Medicine: 2015, 131(1), 131-146

Table 2

Systematic search strategy: synonyms used.

\begin{tabular}{|c|c|c|}
\hline Databases & Economic crisis & $\begin{array}{l}\text { Alcohol consumption } \\
\text { and alcohol-related } \\
\text { health problems }\end{array}$ \\
\hline $\begin{array}{l}\text { MEDLNE } \\
\text { Web of Science } \\
\text { Embase } \\
\text { PsycINFO } \\
\text { Sociological Abstracts } \\
\text { EconLit }\end{array}$ & $\begin{array}{l}\text { Fiscal cris* } \\
\text { Austerit* } \\
\text { Economic/financial AND } \\
\text { Recession* } \\
\text { Depression* } \\
\text { Cris* } \\
\text { Development* } \\
\text { Problem* } \\
\text { Decline* } \\
\text { Downturn* } \\
\text { Stress* } \\
\text { Strain* } \\
\text { Polic* }\end{array}$ & $\begin{array}{l}\text { Alcohol* } \\
\text { Drinking } \\
\text { Drinker* } \\
\text { Alcohol/drinking AND } \\
\text { Behavio* } \\
\text {-related disorder* } \\
\text {-induced disorder* } \\
\text { Disorder* } \\
\text { Problem* } \\
\text { Alcohol AND } \\
\text { Beverage* } \\
\text { Addict* } \\
\text { Abuse* } \\
\text { Misuse* } \\
\text { Use }^{*} \\
\text { Depend }^{*} \\
\text { Consumption }\end{array}$ \\
\hline
\end{tabular}


Goeij, de M.C.M., Suhrcke, M., Toffolutti, V., Mheen, D. van de, Schoenmakers, T.M., Kunst, A.En How economic crises affect alcohol consumption and alcohol-related health problems: a realist systematic review. Social Science \& Medicine: 2015, 131(1), 131-146

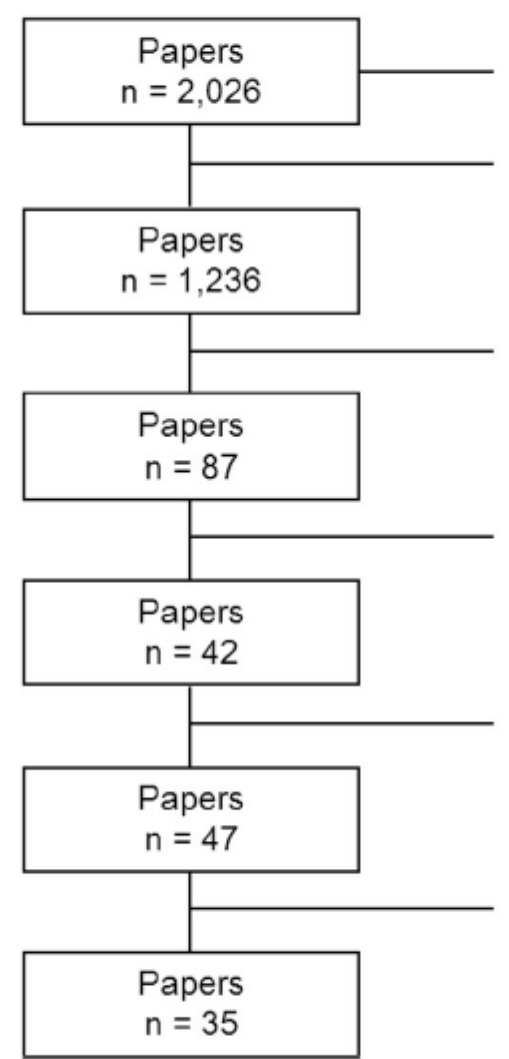

Web of Science: $n=443$

MEDLINE: $n=349$

PsycINFO: $n=249$

Embase: $n=779$

EconLit: $n=40$

Sociological Abstracts: $n=166$

Exclusion of duplicates: $n=790$

Exclusion based on title $(n=599)$ or abstract $(n=550)$

Exclusion based on full text: $n=45$

- Full text not available: $n=10$

- Determinant/outcome: $n=10$

$-<1990: n=4$

- No peer-reviewed empirical evidence: $n=15$

- No mechanism: $\mathrm{n}=6$

Inclusion based on checking cited references in included papers: $n=5$

\section{Exclusion of papers providing "small" evidence for a mechanism: $n=12$}

Fig. 2. Flow diagram.

Table 3

Number of studies, with distinction according to detail of description, coverage of evidence, and study design.

\begin{tabular}{|c|c|c|c|c|c|c|c|}
\hline \multirow[t]{2}{*}{ Mechanism } & \multirow{2}{*}{$\begin{array}{l}\mathrm{N} \text { of } \\
\text { studies }\end{array}$} & \multicolumn{2}{|c|}{ Detail of description } & \multicolumn{2}{|c|}{ Coverage of evidence } & \multicolumn{2}{|l|}{ Study design } \\
\hline & & Thin & Thick & Moderate & Broad & Cross-sectional & Longitudinal \\
\hline M1 Fear of job loss or income reductions and psychological distress & 0 & 0 & 0 & 0 & 0 & 0 & 0 \\
\hline M2 Actual job loss or income reductions and psychological distress & 22 & 4 & 18 & 11 & 11 & 17 & 5 \\
\hline M3 Income reductions and tighter individual budget constraints & 19 & 3 & 16 & 11 & 8 & 15 & 4 \\
\hline M4 Job loss and social situation & 5 & 2 & 3 & 5 & 0 & 4 & 1 \\
\hline M5 Less working time and more non-working time and unhealthy activities & 2 & 1 & 1 & 2 & 0 & 1 & 1 \\
\hline
\end{tabular}


Goeij, de M.C.M., Suhrcke, M., Toffolutti, V., Mheen, D. van de, Schoenmakers, T.M., Kunst, A.En How economic crises affect alcohol consumption and alcohol-related health problems: a realist systematic review. Social Science \& Medicine: 2015, 131(1), 131-146

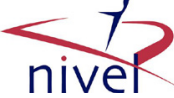

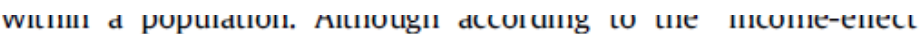
theory" alcohol consumption may decrease in the population as a whole, these differential effects between subgroups may contribute to growing health inequalities during an economic crisis.

\section{Appendix}

Table 1

Study characteristics.

\begin{tabular}{|c|c|c|c|c|c|c|c|}
\hline Author(s), year, journal & Country & Context of country & Mechanism & Determinant/outcome & $\begin{array}{l}\text { Study } \\
\text { population }\end{array}$ & Results & Degree of coverage ${ }^{a}$ \\
\hline $\begin{array}{l}\text { Asgeirsdottir et al., } \\
\text { 2014, Economics and } \\
\text { Human Biology }\end{array}$ & Iceland & $\begin{array}{l}\text { Post- } 2008 \text { economic } \\
\text { crisis, Strong social } \\
\text { support system }\end{array}$ & $\begin{array}{l}\text { Psychological } \\
\text { distress; } \\
\text { Budget } \\
\text { constraints; } \\
\text { Non-working } \\
\text { time (=thin/ } \\
\text { moderate); } \\
\text { Social situation } \\
\text { (=thin/small) }\end{array}$ & $\begin{array}{l}\text { Post- } 2008 \text { economic } \\
\text { crisis and real price } \\
\text { increase (macro)/Heavy } \\
\text { drinking; } \geq 5 \text { drinks on } \\
\text { one day, } \geq 1 \text { times a } \\
\text { month during last year } \\
\text { (micro) }\end{array}$ & $\begin{array}{l}\text { General } \\
\text { population: } \\
18-79 \text { years }\end{array}$ & $\begin{array}{l}\text { Economic crisis (only in } \\
\text { men; effect is not } \\
\text { mediated through } \\
\text { hours of work, real } \\
\text { household income, loss } \\
\text { in financial assets, } \\
\text { increased mortgage } \\
\text { debt, or anxiety/poor } \\
\text { mental health) and real } \\
\text { price increase led to a } \\
\text { reduction in heavy } \\
\text { drinking }\end{array}$ & $\begin{array}{l}\text { Evidence: thick/ } \\
\text { broad } \\
\text { Study design: } \\
\text { longitudinal } \\
\text { (survey) }\end{array}$ \\
\hline $\begin{array}{l}\text { Baker, } 2011 \text {, Journal of } \\
\text { Trauma }\end{array}$ & Russia & $\begin{array}{l}\text { Economic and social } \\
\text { transition ( }>1990) \text {, } \\
\text { Strong binge drinking } \\
\text { culture }\end{array}$ & $\begin{array}{l}\text { Psychological } \\
\text { distress }\end{array}$ & $\begin{array}{l}\text { Transition 1991-1994 } \\
\text { (macro)/Alcohol } \\
\text { consumption per capita } \\
\text { and alcohol-related } \\
\text { mortality (macro) }\end{array}$ & $\begin{array}{l}\text { General } \\
\text { population }\end{array}$ & $\begin{array}{l}\text { Increased alcohol } \\
\text { consumption after } \\
\text { transition, which } \\
\text { coincides with mortality } \\
\text { caused by accidents and } \\
\text { adverse effects }\end{array}$ & $\begin{array}{l}\text { Evidence: thin/ } \\
\text { small } \\
\text { Study design: } \\
\text { repeated cross- } \\
\text { sectional (country } \\
\text { statistics) }\end{array}$ \\
\hline
\end{tabular}

